\title{
Effects of fermented feed on growth performance, nutrient metabolism and cecal microflora of broilers
}

\author{
Jiantao $\mathrm{Li}^{1}$, Lijuan Tao ${ }^{1}$, Rong Zhang ${ }^{1}$, and Guiqin Yang ${ }^{1}$,*
}

\author{
* Corresponding Author: Guiqin Yang \\ Tel: +86-024-88487156, \\ Fax: +86-024-88487156 \\ E-mail: yguiqin@syau.edu.cn
}

${ }^{1}$ College of Animal Science and Veterinary Medicine, Shenyang Agricultural University, Shenyang, Liaoning Province, 110866, China

ORCID

Jiantao Li

https://orcid.org/0000-0003-0596-8902

Lijuan Tao

https://orcid.org/0000-0001-5439-6715

Rong Zhang

https://orcid.org/0000-0001-5181-5953

Guiqin Yang

https://orcid.org/0000-0003-1257-0150

Submitted Jul 25, 2021; Revised Aug 30, 2021; Accepted Sept 21, 2021
Objective: To investigate the effects of enzyme-bacteria co-fermented feed on broilers, the basal diet (BF) was pretreated by microbial enzyme co-fermentation, and then different proportions of $\mathrm{BF}$ were replaced to study its effects on growth performance, nutrient metabolism and cecal microflora of broilers.

Methods: Four hundred and eighty 1-day-old broilers were randomly divided into 6 groups. The control group was fed with $\mathrm{BF}$, and groups 1 to 4 were treated with dried fermented feed (DFF) instead of $10 \%, 15 \%, 20 \%$, and $25 \%$ the BF, and group 5 was treated with wet fermented feed (WFF) instead of 10\% the BF, named BF, 10\% DFF, $15 \%$ DFF, 20\% DFF, $25 \%$ DFF, and $10 \%$ WFF, respectively. The trial period was 42 days.

Results: The results showed that the average daily feed intake and average daily gain of $10 \%$ DFF, $15 \%$ DFF, and 10\% WFF groups were significantly higher than those of the control group at 22 to 42 days and 1 to 42 days $(\mathrm{p}<0.05)$. Except for 10\% DFF group, Firmicutes of all treatment were higher than that of control group. The Bacteroides of each treatment group were lower than that of the control group ( $p>0.05$ ). At the same time, the nutrient apparent metabolic rate and cecal microbial abundance of each treatment group had an increasing trend $(\mathrm{p}>0.05)$.

Conclusion: In conclusion, the feed fermented by enzyme and bacteria had a potential promoting effect on the growth performance and nutrient digestibility of broilers.

Keywords: Broiler; Fermented Feed; Growth Performance; Microflora; Nutrient Metabolism

\section{INTRODUCTION}

With the increasing scarcity of feed resources and the urge for reduced use of antibiotics, it has become the priority target to explore diversified raw materials and efficient production modes. It can be acknowledged that fermented feed has been favored in animal husbandry for its ease of production. Fermented feed refers to the degradation of macromolecular substances in feed into small molecules through microbial metabolism under manual control, to improve the digestibility of macro and micronutrients [1]. Fermentation can decompose or transform the antinutritional factors into non-toxic components, thus reducing the content of antinutritional factors and toxic compounds [2]. Fermentation has gradually become one of the important methods for detoxification of feed mycotoxins. In addition, the positive effects of microorganisms and their metabolites in fermented feed on intestinal health have been confirmed by many researchers. Studies have shown that fermented feed is rich in probiotics and their metabolites, which can improve the intestinal microecological balance and animal immunity [3]. Zhao et al [4] found that adding different proportions of fermented feed to the diet of layers improved the quality of eggs. Also, the conclusion that adding $10 \%$ fermented feed can improve the intestinal microecological balance and reduce the excretion rate of nitrogen and phosphorus was also 
confirmed by Zhao et al [5]. Moreover, the technology of fermented feed preparation by bacteria and enzymes has been gradually recognized by reseachers. Sun et al [6] cofermented cottonseed meal with Bacillus and papain, which significantly reduced the content of crude fat, crude fiber and free gossypol in cottonseed meal. Another result showed that the content of free gossypol and glucosinolates in the miscellaneous meal treated with Saccharomyces cerevisiae, Lactobacillus and cellulase decreased significantly, while the content of crude protein (CP), small peptides and amino acids increased [7]. Although the positive role of fermented feed in livestock breeding has been recognized by many researchers, the application effect of fermented feed prepared under different production processes is not very consistent [8-10]. In addition, the mechanism of the effect of fermented feed on intestinal microecology needs to be further explored [11]. So, to further investigate the effect of fermented feed on broilers, we pretreated the basal diet by microbial enzyme co-fermentation, and then changed the basal diet in different proportions to study its effects on growth performance, nutrient metabolism and cecal microflora of broilers.

\section{MATERIALS AND METHODS}

\section{Experimental design and management of birds}

The management and design of the experiment were kept to animal care rules approved by the Institutional Animal Care and Use Committee of Shenyang Agricultural University (202006046).

A total of 4801 day-old Arbor Acre $\left(\mathrm{AA}^{+}\right)$broilers were randomly assigned to 6 treatments, each with 8 replicates (10 chicks per replicate). The control group was fed with basal $\operatorname{diet}(\mathrm{BF})$ (Table 1), and groups 1 to 4 were treated with dried fermented feed (DFF) instead of $10 \%, 15 \%, 20 \%$, and $25 \%$ $\mathrm{BF}$, and groups 5 was treated with wet fermented feed (WFF) instead of $10 \% \mathrm{BF}$, and were named BF, $10 \% \mathrm{DFF}, 15 \% \mathrm{DFF}$, $20 \%$ DFF, $25 \%$ DFF, and 10\% WFF, respectively.

Birds were reared in multi-tiered brooder cages and raised in climate-controlled rooms at the Shenyang Agricultural University, China. Birds had ad libitum access to feed and water over the trial period. The initial brooding temperature was $35^{\circ} \mathrm{C}$; this was gradually reduced to $21^{\circ} \mathrm{C}$ at 35 days of age and fixed at this level until the end of the experiment. Twenty-four hours of lighting were provided uninterrupted every day.

\section{Preparation of fermented feed}

First, corn, soybean meal, corn gluten meal, dried distillers grains with solubles (DDGS) and wheat bran were prepared into the air dried feed to be fermented according to the proportion provided by the basal diet (Table 2). Then the lactic acid bacteria were inoculated in MRS (De Man, Rogosa, and
Table 1. Basal diet composition and nutrient level of broilers (air dry basis, \%)

\begin{tabular}{lcc}
\hline \multirow{2}{*}{ Items } & \multicolumn{2}{c}{ Content } \\
\cline { 2 - 3 } & $\mathbf{1}$ to $\mathbf{2 1} \mathbf{~ d}$ & $\mathbf{2 2}$ to $\mathbf{4 2} \mathbf{~ d}$ \\
\hline Ingredients & & \\
Corn & 56.50 & 55.40 \\
Soybean meal & 25.55 & 22.20 \\
Corn gluten meal & 4.60 & 3.00 \\
DDGS & 3.00 & 3.00 \\
Wheat bran & - & 3.50 \\
Soybean oil & 1.00 & 3.50 \\
Extruded soybean powder & 5.00 & 5.00 \\
Limestone & 1.20 & 1.20 \\
CaHPO & 1.80 & 1.80 \\
NaCl & 0.25 & 0.30 \\
Choline chloride & 0.10 & 0.10 \\
Premix ${ }^{1)}$ & 1.00 & 1.00 \\
Total & 100.00 & 100.00 \\
Nutrient content ${ }^{2)}$ & & \\
ME (MJ/kg) & 12.42 & 12.78 \\
CP & 20.77 & 18.53 \\
DM & 87.36 & 87.38 \\
EE & 4.45 & 6.91 \\
Ca & 1.08 & 0.96 \\
Total P & 0.68 & 0.68 \\
Available P & 0.45 & 0.42 \\
Lysine & 1.11 & 0.98 \\
Methionine & 0.48 & 0.44 \\
Threonine & 0.73 & 0.65 \\
Tryptophan & 0.19 & 0.18 \\
\hline DD & & \\
\hline
\end{tabular}

DDGS, dried distillers grains with solubles; $\mathrm{ME}$, metabolizable energy; $\mathrm{CP}$, crude protein; DM, dry matter; EE, ether extract.

1) Premix provided nutrients value of diet (/kg): Cu $25 \mathrm{mg}, \mathrm{I} 1.0 \mathrm{mg}$, Fe 100 mg, Mn 120 mg, Se 0.15 mg, Zn 80 mg; vitamin A 18,000 IU, vitamin $D_{3} 2,800 \mathrm{IU}$, vitamin $E \geq 90 \mathrm{mg}$, vitamin $\mathrm{K}_{3} \geq 7.2 \mathrm{mg}$, vitamin $\mathrm{B}_{1} \geq 6.84$ $\mathrm{mg}$, vitamin $\mathrm{B}_{2} \geq 27 \mathrm{mg}$, vitamin $\mathrm{B}_{6} \geq 13.5 \mathrm{mg}$, vitamin $\mathrm{B}_{12} \geq 0.108 \mathrm{mg}$, nicotinamide $\geq 108 \mathrm{mg}$, calcium pantothenate $\geq 45 \mathrm{mg}$, folic acid $\geq 19.8$ $\mathrm{mg}$, biotin $\geq 0.72 \mathrm{mg}$.

2) Proximate nutrients are measured values, other nutrients are calculated values.

Sharp) liquid medium at $2 \%$ and incubated at $35^{\circ} \mathrm{C}$ for $12 \mathrm{~h}$ to prepare starter culture. The starter culture was inoculated into the air dried feed to be fermented, and the moisture content was adjusted to $30 \%$. The fermented feed was put into a breathing bag with a one-way breathing valve (only

Table 2. Composition of enzyme-bacteria co-fermented feed (air-dry basis, \%)

\begin{tabular}{lcc}
\hline Ingredients & $\mathbf{1}$ to $\mathbf{2 1}$ days & $\mathbf{2 2}$ to $\mathbf{4 2}$ days \\
\hline Corn & 63.02 & 63.61 \\
Soybean meal & 28.51 & 25.49 \\
Corn gluten meal & 5.13 & 3.44 \\
DDGS & 3.34 & 3.44 \\
Wheat bran & - & 4.02 \\
Total & 100.00 & 100.00 \\
\hline
\end{tabular}

DDGS, dried distillers grains with solubles. 
exhaust but not intake). The temperature was $32^{\circ} \mathrm{C}$ for anaerobic fermentation for 5 days. The $\mathrm{pH}$ was recorded before and after fermentation.

\section{Growth performance}

The birds were weighed at $1 \mathrm{~d}, 21 \mathrm{~d}$, and $42 \mathrm{~d}$, the leftover feed was recorded every day to measure the average daily feed intake (ADFI), average daily gain (ADG), and ADFI/ ADG (F/G). ADFI, ADG, and F/G data were corrected for mortality.

\section{Apparent metabolic rate}

The total fecal collection method was used to test the metabolizable energy and nutrient metabolism rate of feed in 38 to 42 days. Each morning, all the remaining feed in the trough was recovered, and the actual daily feed intake of each replicate chicken was accurately recorded. At 8 am, a scraping board was used to collect all the excrement on the cardboard, and the data were recorded. The feathers, feed and dander mixed in the excreta were picked up. The excreta were collected for 4 days continuously. All excreta collected for 4 days were dried in $65^{\circ} \mathrm{C}$ oven to constant weight and weighed after 24 hours to determine moisture loss. Then smashed, passed through a 40 mesh sieve (mesh diameter is $0.45 \mathrm{~mm}$ ), mixed well. The method of total energy and chemical components were determined according to the method of Zhang [12].

\section{Sample collection}

At the end of the experiment, six chickens in each treatment were randomly selected and killed by venous bloodletting. The cecum was dissected, and the contents were extruded into a cryopreservation tube and stored at $-80^{\circ} \mathrm{C}$. Then, the $16 \mathrm{~S}$ rRNA microbial sequencing of cecal contents was conducted.

The determination of cecal microflora

The extraction and concentration detection of DNA were carried out according to Li [13]. Then prepare polymerase chain reaction (PCR) amplification reaction system in sterile PCR tube (Table 3). The reaction procedure for PCR was showed in Table 4. During the second PCR amplification,

Table 3. Reaction system for first polymerase chain reaction

\begin{tabular}{lc}
\hline Ingredients & Volume \\
\hline $2 \times$ Hieff Robust PCR Master Mix & $15 \mu \mathrm{L}$ \\
Bar-PCR primer F & $1 \mu \mathrm{L}$ \\
Primer R & $1 \mu \mathrm{L}$ \\
PCR product & 10 to $20 \mathrm{ng}$ \\
$\mathrm{H}_{2} \mathrm{O}$ & 9 to $12 \mu \mathrm{L}$ \\
Total volume & $30 \mu \mathrm{L}$ \\
\hline
\end{tabular}

PCR, polymerase chain reaction.
Table 4. First round polymerase chain reaction amplification reaction procedure

\begin{tabular}{lcc}
\hline Reaction temperature $\left({ }^{\circ} \mathbf{C}\right)$ & Reaction time & \\
\hline 94 & $3 \mathrm{~min}$ & \\
94 & $30 \mathrm{~s}$ & 5 cycles \\
45 & $20 \mathrm{~s}$ & \\
65 & $30 \mathrm{~s}$ & 20 cycles \\
94 & $20 \mathrm{~s}$ & \\
55 & $20 \mathrm{~s}$ & \\
72 & $30 \mathrm{~s}$ & \\
72 & $5 \mathrm{~min}$ & \\
\hline
\end{tabular}

the reaction system and reaction procedure are shown in Table 5 and 6, respectively. At the end of the PCR, 1\% agarose gel electrophoresis was carried out. The electrophoresis voltage was $130 \mathrm{~V}$ and the time was $20 \mathrm{~min}$. Photographs were taken in the UV Gel imaging system and preserved. DNA purification, recovery and quantification. Bioinformatics analysis of cecal microflora: after the samples were processed, Shenggong Bioengineering Co., Ltd. (Shanghai, China) was entrusted to conduct high-throughput sequencing.

\section{Statistical analysis}

Data were analyzed by one-way analysis of variance using SAS 9.2. Comparisons of means for treatments were made using Duncan's multiple range tests. Significance was accepted at $\mathrm{p}<0.05$. In addition, the data of microbial sequencing are counted on the platform provided by Shenggong Bioengineering Co., Ltd. (China).

\section{RESULTS}

\section{Comparison of nutritional components of feed before}

Table 5. Reaction system for second polymerase chain reaction

\begin{tabular}{lc}
\hline Ingredients & Volume \\
\hline $2 \times$ Hieff Robust PCR Master Mix & $15 \mu \mathrm{L}$ \\
Primer F & $1 \mu \mathrm{L}$ \\
Index-PCR Primer R & $1 \mu \mathrm{L}$ \\
PCR products & 20 to $30 \mathrm{ng}$ \\
$\mathrm{H}_{2} \mathrm{O}$ & 9 to $12 \mu \mathrm{L}$ \\
Total volume & $30 \mu \mathrm{L}$ \\
\hline
\end{tabular}

$\mathrm{PCR}$, polymerase chain reaction.

Table 6. Second round polymerase chain reaction amplification reaction procedure

\begin{tabular}{lcc}
\hline Reaction temperature $\left({ }^{\circ} \mathbf{C}\right)$ & Reaction time & \\
\hline 95 & $3 m i n$ & 5 cycles \\
94 & $20 \mathrm{~s}$ & \\
55 & $20 \mathrm{~s}$ & \\
72 & $30 \mathrm{~s}$ & \\
72 & $5 \mathrm{~min}$ & \\
\hline
\end{tabular}




\section{and after fermentation}

The comparison of nutrients before and after fermentation is shown in Table 7. After fermentation, the total acid, and the number of Lactobacillus increased significantly $(\mathrm{p}<0.05)$. However, $\mathrm{pH}$ decreased significantly $(\mathrm{p}<0.05)$. Compared with the fermented feed, the total acid content, and the number of Lactobacillus in the feed dried at $35^{\circ} \mathrm{C}$ were significantly $(\mathrm{p}<0.05)$ higher than those in the feed not dried. After fermentation, the moisture was reduced to the same level as that before fermentation, and no significant $(\mathrm{p}>0.05)$ changes were found in other general nutritional indexes.

\section{Growth performance}

As shown in Table 8, at 22 to 42 days of age, ADFI and ADG of broilers in the $10 \%$ DFF, $15 \%$ DFF, and 10\% WFF groups were significantly higher than those in the control group $(\mathrm{p}<0.05)$. At 1 to 42 days of age, compared with the control group, the ADFI and ADG of broilers in the 10\% DFF, $15 \%$ DFF, and $10 \%$ WFF groups were significantly increased ( $\mathrm{p}<$ 0.05). Fermented feed (after drying) can replace $10 \%$ to $15 \%$ of basal diet, but the growth performance of broilers cannot be further improved by increasing the proportion of fermented feed.

\section{Apparent metabolic rate}

The nutrient metabolic rate of broilers has a trend of improvement by adding fermented feed (Table 9). Compared with the control group, the apparent digestibility of $\mathrm{CP}$, ether extract (EE), calcium and phosphorus in the diet of broilers were increased but did not reach a significant level $(\mathrm{p}>0.05)$.

\section{Cecal microflora}

After 16S rRNA sequencing, 19 phyla were detected (Table 10 ), and 6 phyla with relative abundance greater than $0.05 \%$ were Firmicutes (68.06\%), Bacteroidetes (24.92\%), Proteobacteria (4.65\%), Synergistetes (1.03\%), Verrucomicrobia (0.16\%), Euryarchaeota (0.09\%), unclassified (0.85\%), others (0.24\%). Firmicum and Bacteroides were the dominant flora. Except for $10 \%$ DFF group, Firmicum of all treatment groups were higher than that of control group. The Bacteroides of each

Table 7. Feed composition changes after fermentation and drying (1-21 d/22-42 d, \%)

\begin{tabular}{lcccc}
\hline Feed & Water & $\mathbf{p H}$ & Total acid & Lactic acid bacteria (CFU/g) \\
\hline Pre-ferm. & $12.65^{\mathrm{a}} / 12.11^{\mathrm{a}}$ & $6.16^{\mathrm{a}} / 6.27^{\mathrm{a}}$ & $0.67^{\mathrm{a}} / 0.72^{\mathrm{a}}$ & $\left(1.98 \times 10^{4}\right)^{\mathrm{a}} /\left(3.90 \times 10^{4}\right)^{\mathrm{a}}$ \\
After ferm. & $31.23^{\mathrm{b}} / 31.57^{\mathrm{b}}$ & $4.14^{\mathrm{b}} / 4.23^{\mathrm{b}}$ & $2.28^{\mathrm{b}} / 2.32^{\mathrm{b}}$ & $\left(1.31 \times 10^{8}\right)^{\mathrm{b}} /\left(1.81 \times 10^{8}\right)^{\mathrm{b}}$ \\
Dry after ferm. & $12.98^{\mathrm{a}} / 12.55^{\mathrm{a}}$ & $4.32^{\mathrm{c}} / 4.21^{\mathrm{b}}$ & $2.86^{\mathrm{c}} / 3.13^{\mathrm{c}}$ & $\left(3.57 \times 10^{6}\right)^{\mathrm{a}} /\left(2.77 \times 10^{6}\right)^{\mathrm{a}}$ \\
SEM & $3.07 / 3.21$ & $0.32 / 0.34$ & $0.34 / 0.35$ & $2.35 \times 10^{7} / 3.05 \times 10^{7}$ \\
p-value & $\mathrm{p}<0.001 / \mathrm{p}<0.001$ & $\mathrm{p}<0.001 / \mathrm{p}<0.001$ & $\mathrm{p}<0.001 / \mathrm{p}<0.001$ & $\mathrm{p}<0.004 / \mathrm{p}<0.001$ \\
\hline
\end{tabular}

CFU, colony-forming unit; SEM, standard error of the mean.

${ }^{a-c}$ Values within a column with no or the same letter superscripts mean no significant difference $(p>0.05)$; values with different small letter superscripts mean significant difference $(p<0.05)$.

Table 8. Effect of the fermented feed on growth performance of broilers (g)

\begin{tabular}{|c|c|c|c|c|c|c|c|c|}
\hline \multirow{2}{*}{ Items } & \multicolumn{6}{|c|}{ Treatments $^{1)}$} & \multirow{2}{*}{ SEM } & \multirow{2}{*}{ p-value } \\
\hline & BF & $10 \%$ DFF & $15 \%$ DFF & $20 \%$ DFF & $25 \%$ DFF & $10 \%$ WFF & & \\
\hline \multicolumn{9}{|l|}{1 to 21 days } \\
\hline ADFI & 43.33 & 43.57 & 43.87 & 43.37 & 43.87 & 45.08 & 0.25 & 0.341 \\
\hline ADG & 31.1 & 32.22 & 32.22 & 31.7 & 31.14 & 32.12 & 0.18 & 0.2 \\
\hline$F / G$ & 1.39 & 1.35 & 1.36 & 1.37 & 1.41 & 1.41 & 0.01 & 0.257 \\
\hline Mortality/\% & 0 & 1.25 & 0 & 1.25 & 0 & 0 & - & - \\
\hline \multicolumn{9}{|l|}{22 to 42 days } \\
\hline ADFI & $106.46^{\mathrm{a}}$ & $111.76^{b}$ & $114.41^{b}$ & $107.35^{a}$ & $106.66^{a}$ & $111.69^{b}$ & 0.68 & $<0.001$ \\
\hline ADG & $62.67^{\mathrm{a}}$ & $66.56^{b}$ & $68.18^{b}$ & $65.43^{\mathrm{ab}}$ & $62.84^{a}$ & $67.56^{b}$ & 0.49 & $<0.001$ \\
\hline$F / G$ & 1.7 & 1.68 & 1.68 & 1.64 & 1.7 & 1.66 & 0.01 & 0.452 \\
\hline Mortality/\% & 1.25 & 0 & 0 & 2.5 & 1.25 & 3.75 & - & - \\
\hline \multicolumn{9}{|l|}{1 to 42 days } \\
\hline ADFI & $74.06^{a}$ & $77.67^{b}$ & $79.14^{b}$ & $74.10^{a}$ & $74.70^{a}$ & $78.45^{b}$ & 0.49 & $<0.001$ \\
\hline ADG & $47.23^{\mathrm{a}}$ & $50.51^{b}$ & $51.39^{b}$ & $49.49^{a b}$ & $47.91^{\mathrm{ab}}$ & $50.74^{b}$ & 0.31 & $<0.001$ \\
\hline$F / G$ & 1.57 & 1.54 & 1.54 & 1.5 & 1.56 & 1.54 & 0.02 & 0.139 \\
\hline Mortality/\% & 1.25 & 1.25 & 0 & 3.75 & 1.25 & 3.75 & - & - \\
\hline
\end{tabular}

SEM, standard error of the mean; ADFI, average daily feed intake; ADG, average daily gain; F/G, average daily feed intake/average daily gain.

1) BF, basal diet; DFF, dried fermented feed; WFF, wet fermented feed.

${ }^{a, b}$ Values within a row with no or the same letter superscripts mean no significant difference $(p>0.05)$; values with different small letter superscripts mean significant difference $(p<0.05)$ 
Table 9. Effect of the fermented feed on nutrient metabolic rate of broilers (\%)

\begin{tabular}{|c|c|c|c|c|c|c|c|c|}
\hline \multirow{2}{*}{ Items } & \multicolumn{6}{|c|}{ Treatments $^{1)}$} & \multirow{2}{*}{ SEM } & \multirow{2}{*}{ p-value } \\
\hline & $\mathrm{BF}$ & $10 \%$ DFF & $15 \%$ DFF & $20 \%$ DFF & $25 \%$ DFF & $10 \%$ WFF & & \\
\hline DM & 69.07 & 72.35 & 71.01 & 71.8 & 70.88 & 69.3 & 0.58 & 0.533 \\
\hline $\mathrm{CP}$ & 49.55 & 55.64 & 54.87 & 56.64 & 54.7 & 54.6 & 0.91 & 0.295 \\
\hline $\mathrm{EE}$ & 71.44 & 81.44 & 77.65 & 77.5 & 76.68 & 78.44 & 0.94 & 0.06 \\
\hline $\mathrm{Ca}$ & 37.5 & 40.63 & 48.49 & 42.64 & 41.21 & 39.73 & 0.19 & 0.138 \\
\hline$P$ & 36.61 & 41.15 & 38.8 & 40.95 & 40.05 & 41.73 & 1.16 & 0.412 \\
\hline Energy & 73.62 & 76.73 & 75.76 & 74.71 & 73.91 & 73.66 & 0.59 & 0.598 \\
\hline
\end{tabular}

SEM, standard error of the mean; DM, dry matter; CP, crude protein; EE, ether extract.

1) BF, basal diet; DFF, dried fermented feed; WFF, wet fermented feed.

Values within a column with no letter superscripts mean no significant difference $(p>0.05)$

Table 10. Effect of the fermented feed on proportion of bacteria at phylum level in broilers (\%)

\begin{tabular}{|c|c|c|c|c|c|c|c|c|}
\hline \multirow{2}{*}{ Items } & \multicolumn{6}{|c|}{ Treatments ${ }^{1)}$} & \multirow{2}{*}{ SEM } & \multirow{2}{*}{ p-value } \\
\hline & BF & $10 \%$ DFF & $15 \%$ DFF & $20 \%$ DFF & $25 \%$ DFF & $10 \%$ WFF & & \\
\hline Firmicutes & 63.23 & 59.67 & 76.44 & 68.31 & 70 & 70.7 & 2.11 & 0.26 \\
\hline Bacteroidetes & 32.05 & 31.85 & 13.73 & 21.87 & 23.77 & 26.38 & 2.41 & 0.238 \\
\hline Proteobacteria & 2.57 & 6.85 & 6.25 & 7.9 & 2.69 & 1.63 & 0.98 & 0.296 \\
\hline Synergistetes & $0.87^{\mathrm{ab}}$ & $0.52^{\mathrm{ab}}$ & $2.02^{a}$ & $0.97^{b}$ & $1.46^{\mathrm{ab}}$ & $0.34^{b}$ & 0.17 & 0.035 \\
\hline Unclassified & 0.81 & 0.83 & 1.32 & 0.75 & 0.8 & 0.59 & 0.08 & 0.122 \\
\hline Actinobacteria & 0.17 & 0.14 & 0.14 & 0.13 & 0.23 & 0.15 & 0.02 & 0.642 \\
\hline Euryarchaeota & $0.24^{\mathrm{a}}$ & $0.04^{b}$ & $0.05^{b}$ & $0.02^{b}$ & $0.06^{b}$ & $0.13^{\mathrm{ab}}$ & 0.02 & 0.035 \\
\hline Others & 0.06 & 0.09 & 0.05 & 0.06 & 0.1 & 0.09 & 0.15 & 0.408 \\
\hline
\end{tabular}

SEM, standard error of the mean.

1) $\mathrm{BF}$, basal diet; DFF, dried fermented feed; WFF, wet fermented feed

$a, b$ Values within a row with no or the same letter superscripts mean no significant difference $(p>0.05)$; values with different small letter superscripts mean significant difference $(p<0.05)$

treatment group were lower than that of the control group, but the difference was not significant $(\mathrm{p}>0.05)$.
At genus level, 14 genera with relative abundance greater than $1 \%$ were detected (Table 11). They were: Alistipes (16.64\%),

Table 11. Effect of the fermented feed on proportion of bacteria at genus level in broilers (\%)

\begin{tabular}{|c|c|c|c|c|c|c|c|c|}
\hline \multirow{2}{*}{ Items } & \multicolumn{6}{|c|}{ Treatments $^{1)}$} & \multirow{2}{*}{ SEM } & \multirow{2}{*}{ p-value } \\
\hline & BF & $10 \%$ DFF & $15 \%$ DFF & $20 \%$ DFF & $25 \%$ DFF & $10 \%$ WFF & & \\
\hline Unclassified & 38.15 & 37.68 & 48.45 & 35.97 & 47.17 & 40.11 & 2.09 & 0.396 \\
\hline Alistipes & 24.64 & 21.76 & 9.03 & 14.69 & 12.52 & 17.18 & 1.75 & 0.090 \\
\hline Ruminococcus & $3.86^{b}$ & $6.24^{\mathrm{ab}}$ & $2.59^{b}$ & $3.79^{b}$ & $3.71^{b}$ & $8.58^{a}$ & 0.53 & 0.008 \\
\hline Lactobacillus & 3.65 & 1.84 & 9.88 & 6.02 & 2.19 & 2.37 & 0.94 & 0.092 \\
\hline Faecalibacterium & 4.44 & 4.19 & 2.91 & 7.77 & 2.83 & 3.40 & 0.78 & 0.471 \\
\hline Bacteroides & 2.04 & 4.34 & 1.39 & 2.35 & 6.20 & 2.99 & 0.51 & 0.063 \\
\hline Subdoligranulum & 3.07 & 1.06 & 5.43 & 1.97 & 1.27 & 3.84 & 0.57 & 0.202 \\
\hline Romboutsia & 1.69 & 2.62 & 3.04 & 3.08 & 1.72 & 0.62 & 0.58 & 0.820 \\
\hline Barnesiella & 1.97 & 1.42 & 1.87 & 1.56 & 1.73 & 3.27 & 0.40 & 0.824 \\
\hline Clostridium XIVa & 1.17 & 1.54 & 1.22 & 2.14 & 2.72 & 2.14 & 0.24 & 0.401 \\
\hline Clostridium IV & 1.47 & 1.82 & 1.42 & 1.11 & 2.03 & 1.24 & 0.11 & 0.105 \\
\hline Bilophila & 0.59 & 0.52 & 2.51 & 4.14 & 0.40 & 0.70 & 0.60 & 0.378 \\
\hline Butyricicoccus & 1.55 & 0.87 & 0.89 & 0.85 & 1.69 & 1.98 & 0.20 & 0.438 \\
\hline Vampirovibrio & 1.02 & 1.89 & 1.90 & 0.66 & 0.93 & 0.46 & 0.29 & 0.596 \\
\hline Dorea & 0.99 & 1.68 & 0.54 & 1.02 & 0.94 & 1.16 & 0.17 & 0.577 \\
\hline
\end{tabular}

SEM, standard error of the mean.

1) BF, basal diet; DFF, dried fermented feed; WFF, wet fermented feed.

$a, b$ Values within a row with no or the same letter superscripts mean no significant difference $(p>0.05)$; values with different small letter superscripts mean significant difference $(p<0.05)$. 
Luminococcus (4.79\%), Lactobacillus (4.33\%), Faecalibacterium (4.26\%), Faecalibacterium (3.22\%), Subdoligranulum (2.77\%), Romboutsia (2.13\%), Barnesiella (1.97\%), Clostridium xlva (1.82\%), Clostridium IV (1.51\%), Bilophila (1.48\%), Butyricoccus (1.31\%), Vampirovibrio (1.14\%), Dorea (1.06\%), Unclassified (41.25\%). The proportion of Alistipes, Ruminococcus, Lactobacillus and Bacteroides in cecum of broilers were changed by adding fermented feed, but only Ruminococcus was significantly affected $(\mathrm{p}<0.05)$.

\section{Microbial diversity}

The abundance and diversity of cecal microflora can be reflected by alpha diversity analysis (Table 12). The sequencing coverage of each group of samples is more than $98.6 \%$, and the depth is enough to reflect the microflora in the samples. Adding fermented feed could increase the Chao 1 and ACE index of cecal microflora in broilers, but it did not reach a significant level $(\mathrm{p}>0.05)$.

\section{DISCUSSION}

\section{Growth performance}

Fermented feed can degrade macromolecular and antinutritional factors in raw materials under the action of microorganisms, thereby increasing feed digestibility and absorption, resulting in improved growth performance of broilers $[14,15]$. The effect of fermentation on nutrient digestibility and utilization of feed has been confirmed in mink and salmon $[16,17]$. Microorganisms and their metabolites can improve the intestinal microecological environment, enhance the resistance to diseases, and contribute to the maintenance of intestinal health, which is an effective alternative strategy for antibiotics. Using the synergistic effect of microorganisms and enzymes to predigest the feed can make the degradation of macromolecular substances in the feed more thorough, the microbial fermentation efficiency is higher, and the effect on broilers is better than single fermentation or enzymatic hydrolysis [18].

Growth performance is an important index of feed fer- mentation quality. Chen et al [19] fed broilers with different proportions of fermented feed (Lactobacillus and Bacillus subtilis as fermentation strains) instead of complete formula feed. The results showed that when the proportion of fermented feed was $10 \%$, ADG of broilers could be increased and F/G could be reduced. Li et al [20] showed that adding $10 \%$ and $15 \%$ fermented complete formula feed to broiler diet could improve ADG and reduce F/G. The results showed that adding $10 \%$ and $15 \%$ fermented feed could increase ADFI and ADG and reduce F/G of broilers aged 22 to $42 \mathrm{~d}$ and 1 to $42 \mathrm{~d}$, which was consistent with the previous reports. However, at the age of 1 to $21 \mathrm{~d}$, the F/G of broilers with $25 \%$ fermented material or $10 \%$ wet fermented material increased. The results showed that the digestibility of organic matter in ruminants and monogastric animals decreased by $0.65 \%$ to $0.70 \%$ and $1.35 \%$ to $1.40 \%$ when the level of crude fiber in the diet increased by $1 \%$ [21]. Too much insoluble fiber will shorten the residence time of chyme in the intestine, and too much soluble fiber will adhere to the surface of chyme to form a nutritional barrier, which are not conducive to the digestion of nutrients [22]. In our experiment, with the increase of the proportion of fermented feed, the content of fiber in the diet increased, resulting in the gradual decrease of digestibility. The lower nutrient digestibility of the $10 \%$ group may be due to the excessive growth of microorganisms caused by the high water content of the feed, which consumes the nutrients in the feed and reduces the nutrient concentration.

\section{Nutrient metabolic rate}

Feed fermentation can improve the nutrient metabolism of poultry. It was found that fermented feed could increase the expression of AMY2A and CCK in pancreas of broilers and increase the secretion of amylase and cholecystokinin in pancreas (SUn) [23]. Al-Khalaifah et al [24] found that fermented dry beer grain (DBG) can promote the expression of genes related to digestion and nutrient transport more than enzyme treated DBG, and these genes can regulate the nutrient utilization required by poultry growth. Lawal et al

Table 12. Effect of the fermented feed on cecal microbial alpha diversity in broilers

\begin{tabular}{|c|c|c|c|c|c|c|c|c|}
\hline \multirow{2}{*}{ Items } & \multicolumn{6}{|c|}{ Treatments $^{1)}$} & \multirow{2}{*}{ SEM } & \multirow{2}{*}{ p-value } \\
\hline & BF & $10 \%$ DFF & $15 \%$ DFF & $20 \%$ DFF & $25 \%$ DFF & $10 \%$ WFF & & \\
\hline ACE & $4,481.98$ & $4,826.40$ & $4,347.21$ & $4,709.64$ & $4,737.21$ & 4,854.52 & 160.29 & 0.941 \\
\hline Chao 1 & $3,081.73$ & $3,338.83$ & $2,959.54$ & $3,253.63$ & $3,275.95$ & 3,392.54 & 101.24 & 0.838 \\
\hline Shannon & 4.26 & 4.37 & 4.1 & 4.35 & 4.65 & 4.38 & 0.07 & 0.277 \\
\hline Simpson & 0.07 & 0.06 & 0.07 & 0.06 & 0.03 & 0.05 & 0.01 & 0.395 \\
\hline Coverage & 0.99 & 0.99 & 0.99 & 0.99 & 0.99 & 0.99 & 0.01 & 0.175 \\
\hline
\end{tabular}

SEM, standard error of the mean; ACE, the ACE estimator (http://www.mothur.org/wiki/Ace); Chao 1, the Chao 1 estimator (http://www.mothur.org/wiki/ Chao).

1) BF, basal diet; DFF, dried fermented feed; WFF, wet fermented feed.

Data within a column with no letter superscripts mean no significant difference ( $p>0.05)$. 
[25] reported that broilers fed diets supplemented with fermented palm kernel had higher apparent digestibility of $\mathrm{DM}, \mathrm{N}$, and ash than those in the control. Ahmed et al [26] also obtained similar results. The digestibility of $\mathrm{CP}$ in diets containing fermented rapeseed meal was higher than that in broilers without fermented rapeseed meal.

Nutrient digestibility is a quantitative assessment of nutritional and physiological phenomena related to digestive capacity and intestinal function. In our experiment, the apparent metabolic rates of $\mathrm{EE}$ and $\mathrm{Ca}$ of broilers were increased after adding fermented material. Lactic acid produced by fermentation can decreased the $\mathrm{pH}$ of feed, and then reduce the $\mathrm{pH}$ of digestive tract, which provides a good acidic environment for $\mathrm{Ca}$ absorption. The apparent metabolic rate of CP was increased by adding $20 \%$ fermented feed. This may be because the beneficial microorganisms in the fermentation broth can produce some metabolites, such as lactic acid, bacteriocin, antibacterial substances, higher alcohols, etc., which can reduce the $\mathrm{pH}$ of digestive tract, inhibit, or kill harmful bacteria such as Escherichia coli, and improve the digestion and absorption capacity of intestines [25,27]. In this experiment, with the increase of the proportion of fermented feed, the apparent digestibility of nutrients increased first and then decreased. It is suggested that the proportion of fermented feed in animal feed should be further explored.

\section{Cecal microflora structure}

Intestinal microflora have positive effects on the host in many ways, such as regulating intestinal motility and immune homeostasis, promoting nutrient absorption [28], producing vitamins, metabolizing bile acids and sterols [29]. In addition, intestinal flora can also protect the host from pathogens [28] and inflammatory intestinal diseases, thus improving intestinal health. Generally, intestinal flora is affected by many factors, such as diet, age, host genotype, pathogen infection and feed additives. In our experiment, the microbial abundance index and Shannon index in cecum of broilers fed with fermented feed showed an increasing trend compared with the control, and the highest was the $10 \%$ WFF and $10 \%$ DFF, but there was no statistical difference.

At the phylum level, we found that the cecal microflora of all experimental groups were dominated by Bacteroides and Firmicutes, which was consistent with the observation of previous studies [30-33]. The abundance of Firmicutes is often positively correlated with the growth performance of animals [34,35]. At genus level, the abundance of Bacteroides, Clostridium xiva, and Clostridium IV in the cecum of broilers increased with the addition of fermented feed. Propionic acid produced by metabolism of pseudobacteroides can improve intestinal barrier function. In addition, Bacteroides have many genes required for polysaccharide metabolism $[36,37]$. In this experiment, the proportion of Clostridium xiva increased in all the treatment groups, while the proportion of Clostridium IV in 10\% DFF and 25\% DFF increased. The fermentation products of these two strains were mainly butyric acid. Butyric acid can stabilize the intestinal state, and provide energy to the body, so as to promote the growth of animals [38]. In conclusion, adding fermented feed can improve intestinal flora of broiler.

\section{CONCLUSION}

Our results strongly indicated that the enzyme-bacteria cofermented feed had a potential promoting effect on the growth performance and nutrient digestibility of broilers. In addition, the positive effects of enzyme-bacteria co-fermented feed on improving the intestinal microenvironment and optimizing the intestinal microflora structure were further confirmed in our study.

\section{CONFLICT OF INTEREST}

We certify that there is no conflict of interest with any financial organization regarding the material discussed in the manuscript.

\section{FUNDING}

This work was supported by the National Natural Science Foundation of China (31772618).

\section{REFERENCES}

1. Canibe N, Jensen BB. Fermented liquid feed-microbial and nutritional aspects and impact on enteric diseases in pigs. Anim Feed Sci Technol 2012;173:17-40. https://doi.org/10. 1016/j.anifeedsci.2011.12.021

2. Yang LJ, Yang ZB, Yang WR, et al. Conventional solid fermentation alters mycotoxin contents and microbial diversity analyzed by high-throughput sequencing of a Fusarium mycotoxin-contaminated diet. Can J Anim Sci 2018;98:35461. https://doi.org/10.1139/cjas-2017-0093

3. Yang LJ, Xue XS, Song QL, et al. Effects of solid fermentation vinegar grains on growth performance, apparent digestibility of nutrients, serum index and volatile fatty acid content in feces of fattening pigs. Chin J Anim Nutr 2020;32:119-28. https://doi.org/10.3969/j.issn.1006-267x.2020.04.015

4. Zhao CQ. Effects of microbial fermented feed without antibiotics on production performance and egg quality of laying hens. Chin Anim Husb Vet Abstracts 2014;30:172. https://doi.org/10.16003/j.cnki.issn1672-5190.2013.11.040

5. Zhao YE. Effect of microbial fermented feed on intestinal microflora, nitrogen and phosphorus excretion rate of laying hens. Rural Staff 2018;14:223. https://doi.org/CNKI:SUN: 


\section{NJCM.0.2018-14-210}

6. Sun H. Study on the nutritional characteristics of cottonseed meal, preparation of cottonseed peptide and its antioxidant activity. Zhejiang, China: Zhejiang University; 2013.

7. Zhang K. Study on the production of protein feed by solid state fermentation of miscellaneous meal with enzyme. Wuhan, Hubei, China: Wuhan Institute of Technology; 2012.

8. Chaiwang N, Bunmee T, Arjin C, et al. Effect of deep bedding floor and fermented feed supplement on productive performance, carcase, meat quality and fatty acid profile of crossbred pigs. Ital J Anim Sci 2021;20:479-88. https://doi.org/10.1080/ 1828051X.2021.1893133

9. Aslamyah S, Hidayani AA, Badraeni, et al. The organoleptic, physical and chemical quality of mud crab fattening feed fermented with a microorganism mixture. IOP Conf Ser Earth Environ Sci 2021;763:012032. https://doi.org/10.1088/ 1755-1315/763/1/012032

10. Choi W, Dang BS, Hong J, et al. The effect of fermented kefir as functional feed additive in post-weaned pigs. Fermentation 2021;7:23. https://doi.org/10.3390/FERMENTATION7010023

11. Tao Q, Li B, Chen Y, et al. An integrated method to produce fermented liquid feed and biologically modified biochar as cadmium adsorbents using corn stalks. Waste Manag 2021; 127:112-20. https://doi.org/10.1016/J.WASMAN.2021.04.027

12.Zhang LY. Feed analysis and feed quality testing technology (2nd Edition). Beijing, China: China Agricultural University Press; 2007.

13. Li X. Effects of soybean oligosaccharides on growth, immune, skatole concentration in excreta and cecal microflora structure in broilers. Shenyang, Liaoning, China: Shenyang Agricultural University; 2018.

14. Chiang G, Lu WQ, Piao XS, Hu JK, Gong LM, Thacker PA. Effects of feeding solid-state fermented rapeseed meal on performance, nutrient digestibility, intestinal ecology and intestinal morphology of broiler chickens. Asian-Australas J Anim Sci 2010;23:263-71. https://doi.org/10.5713/ajas.2010. 90145

15.Xu FZ, Zeng XG, Ding XL. Effects of replacing soybean meal with fermented rapeseed meal on performance, serum biochemical variables and intestinal morphology of broilers. Asian-Australas J Anim Sci 2012;25:1734-41. https://doi. org/10.5713/ajas.2012.12249

16. Skrede G, Sahlstrøm S, Skrede A, Holck A, Slinde E. Lactic acid fermentation of wheat and barley whole meal flour modifies carbohydrate composition and increases digestibility in mink (Mustela vison). Anim Feed Sci Technol 2001; 90:199-212. https://doi.org/10.1016/S0377-8401(01)00222-X

17. Skrede G, Storebakken T, Skrede A, et al. Lactic acid fermentation of wheat and barley whole meal flours improves digestibility of nutrients and energy in Atlantic salmon (Salmo salar L.) diets. Aquaculture 2002;210:305-21. https://doi.org/ 10.1016/S0044-8486(01)00851-1
18. Cheng YH, Hsiao SH, Wen CM, et al. Mixed fermentation of soybean meal by protease and probiotics and its effects on the growth performance and immune response in broilers. J Appl Anim Res 2019;47:339-48. https://doi.org/10.1080/ 09712119.2019.1637344

19. Chen ZM, Zhang S, Wang ZN, et al. Investigation report on general nutrient content of protein feed resources in China. Grain Feed Ind 2020;1:47-50. https://doi.org/10.16431/j.cnki. 1671-7236.2020.12.013

20.Li L, Chou XX, Yan HJ. Optimization of fermentation conditions for broiler feed and its application effect. Feed Res 2019;42:12-5. https://doi.org/10.13557/j.cnki.issn1002-2813. 2019.04.004

21.Lijie Y, Xinsheng X, Qinglong S, Lijie W, Xiangfang Z, Shiyan Q. Effects of solid-state fermented vinegar lees feed on growth performance, nutrient apparent digestibility, serum indexes and volatile fatty acid content in feces of finishing pigs. Chin J Anim Nutr 2020;32:119-28. https://doi.org/10.3969/j.issn. 1006-267x.2020.04.015

22.Lijie Y, Xiangfang Z, Shiyan Q. Research progress of non starch polysaccharides in the regulation of intestinal flora in pigs. Biotechnology Bulletin 2020;36:9-16. https://doi.org/ 10.13560/j.cnki.biotech.bull.1985.2019-1224

23. Feng J, Liu X, Xu ZR, Wang YZ, Liu JX. Effects of fermented soybean meal on digestive enzyme activities and intestinal morphology in broilers. Poult Sci 2007;86:1149-54. https:// doi.org/10.1093/ps/86.6.1149

24. Al-Khalaifah HS, Shahin SE, Omar AE, Mohammed HA, Mahmoud HI, Ibrahim D. Effects of graded levels of microbial fermented or enzymatically treated dried brewer's grains on growth, digestive and nutrient transporter genes expression and cost effectiveness in broiler chickens. BMC Vet Res 2020; 16:424. https://doi.org/10.1186/s12917-020-02603-0

25.Lawal TE, Iyayi BA, Adeniyi BA, et al. Biodegradation of palm kernel cake with multienzyme complexes from fungi and its feeding value for broilers. Int J Poult Sci 2010;9:695701. https://doi.org/10.3923/ijps.2010.695.701

26. Ahmed A, Zulkifli I, Farjam AS, Abdullah N, Liang JB, Awad EA. Effect of solid state fermentation on nutrient content and ileal amino acids digestibility of canola meal in broiler chickens. Ital J Anim Sci 2014;13:410-4. https://doi.org/10. 4081/ijas.2014.3293

27.Wu QJ, Wang ZB, Wang GY, Li YX, Qi YX. Effects of feed supplemented with fermented pine needles (Pinus ponderosa) on growth performance and antioxidant status in broilers. Poult Sci 2015;94:1138-44. https://doi.org/10.3382/ps/pev 013

28. Kau AL, Ahern PP, Griffin NW, et al. Human nutrition,the gut microbiome and the immune system. Nature 2011;474: 327-36. https://doi.org/10.1038/nature10213

29. Mahony SM, Clarke G, Borre YE, et al. Serotonin, tryptophan metabolism and the brain-gut-microbiome axis. Behav Brain 
Res 2015;277:32-48. https://doi.org/10.1016/j.bbr.2014.07. 027

30. Waite DW, Taylor MW. Characterizing the avian gut microbiota: membership, driving influences, and potential function. Front Microbiol 2014;5:223. https://doi.org/10.3389/fmicb. 2014.00223

31. Yeoman CJ, Chia N, Jeraldo P, et al. The microbiome of the chicken gastrointestinal tract. Anim Health Res Rev 2012; 13:89-99. https://doi.org/10.1017/S1466252312000138

32.Singh P, Karimi A, Devendra K, Waldroup PW, Cho KK, Kwon YM. Influence of penicillin on microbial diversity of the cecal microbiota in broiler chickens. Poult Sci 2013;92: 272-6. https://doi.org/10.3382/ps.2012-02603

33.Stanley D, Geier MS, Denman SE, et al. Identification of chicken intestinal microbiota correlated with the efficiency of energy extraction from feed. Vet Microbiol 2013;164:8592. https://doi.org/10.1016/j.vetmic.2013.01.030

34. Singh KM, Shah T, Deshpande S, et al. High through put 16S rRNA gene-based pyrosequencing analysis of the fecal microbiota of high FCR and low FCR broiler growers. Mol
Biol Rep 2012;39:10595-602. https://doi.org/10.1007/s11033012-1947-7

35.Crisol-Martínez, Stanley D, Geier MS, et al. Understanding the mechanisms of zinc bacitracin and avilamycin on animal production: Linking gut microbiota and growth performance in chickens. Appl Microbiol Biotechnol 2017;101:4547-59. https://doi.org/10.1007/s00253-017-8193-9

36. Martens EC, Chiang HC, Gordon JI. Mucosal glycan foraging enhances fitness and transmission of a saccharolytic human gut bacterial symbiont. Cell Host Microbe 2008;4:447-57. https://doi.org/10.1016/j.chom.2008.09.007

37.Zhang M, Chekan JR, Dodd D, et al. Xylan utilization in human gut commensal bacteria is orchestrated by unique modular organization of polysaccharide-degrading enzymes. Proc Natl Acad Sci USA 2014;111:E3708-17. https://doi.org/ 10.1073/pnas.1406156111

38. Ma YL, Wang JH, Cheng YQ, LJ Yin, LT Li. Some biochemical and physical changes during manufacturing of grey sufu, a traditional Chinese fermented soybean curd. Int J Food Eng 2013;9:45-54. https://doi.org/10.1515/ijfe-2012-0204 